\title{
CARLEMAN ESTIMATES AND UNIQUE CONTINUATION PROPERTY FOR ELLIPTIC OPERATORS IN BANACH SPACES
}

\author{
VELI B. SHAKHMUROV
}

Abstract. The unique continuation theorems for elliptic differential-operator equations in Banachvalued $L_{p}$-space are investigated. The operator-valued multiplier theorems and the Carleman estimates for the equations are employed to obtain these results. In applications the unique continuation theorems for anisotropic elliptic differential equations and finite or infinite systems of elliptic equations are studied.

Mathematics subject classification (2010): 34G10, 35B45, 35B60.

Keywords and phrases: Carleman estimates, unique continuation, Banach-valued function spaces, differential operator equations, operator-valued Fourier multipliers, interpolation of Banach spaces.

\section{REFERENCES}

[1] H. Amann, Linear and quasi-linear equations, 1, Birkhauser, Basel,1995.

[2] N. ARonszajn, A unique continuation theorem for solutions of elliptic partial differential equations or inequalities of second order, J. Math. Purees Appl. 36, 9 (1957), 235-249.

[3] P. Besov, V. P. ILin, S. M. Nikols KiI, Integral representations of functions and embedding theorems, Nauka, Moscow, 1975.

[4] A. Boutet De Monvel-Berthier, An optimal Carleman-type inequality for the Dirac operator, Stochastic processes and their applications in mathematics and physis, Bielefeld 1985, p. 71-94, Math. Appl. 61, Kluwer Akad. Publ. Dordrechet, 1990.

[5] D. L. BURKHOLDER, A geometrical conditions that implies the existence certain singular integral of Banach space-valued functions, Proc. conf. Harmonic analysis in honor of Antonu Zigmund, Chicago, 1981, Wads Worth, Belmont, 1983, 270-286.

[6] J. Bourgain, Some remarks on Banach spaces in which martingale differences are unconditional, Arkiv Math. 21 (1983), 163-168.

[7] Ph. Clement, B. de Pagter, F. A. Sukochev, H. Witvliet, Schauder decomposition and multiplier theorems, Studia Math. 138 (2000), 135-163.

[8] T. CARleman, Sur on problème d'unicité pur les systems d'équations aux dérivées partiells àdeux variables indépendantes, Ark. Mat. Astr. Fys. 26, 17 (1939), 9.

[9] G. DoRe, S. YAKUBov, Semigroup estimates and noncoercive boundary value problems, Semigroup Form 60 (2000), 93-121.

[10] R. Denk, M. HIEBER, J. PRÜSS, R-boundedness, Fourier multipliers and problems of elliptic and parabolic type, Mem. Amer. Math. Soc. 166 (2003), 788.

[11] I.M. Gelfand AND G.E. Shilov, Generalized Functions, v.1, Academic Press, New York, 1964.

[12] R. HALlER, H. HeCK, AND A. NOLL, Mikhlin's theorem for operator-valued Fourier multipliers in $n$ variables, Math. Nachr. 244 (2002), 110-130.

[13] D. JERISON, C. E. KenIG, Unique continuation and absence of positive eigenvalues for Schrodinger operators, Arkiv. Math. 62 (1986), 118-134.

[14] H. Koch, D. TATARU, Carleman estimates and unique continuation for second order elliptic equations with non-smooth coefficients, Comm. Pure Appl. Math. 54, 3 (2001), 330-360.

[15] S. G. KREIN, Linear differential equations in Banach space, American Mathematical Society, Providence, 1971. 
[16] C. E. Kenig, A. Ruiz And C. D. Sogge, Uniform Sobolev inequalities and unique continuation for second order constant coefficient differential operators, Duke Math.J. 55, 2 (1987), 329-347.

[17] P. I. Lizorkin, $\left(L_{p}, L_{q}\right)$-Multiplicators of Fourier Integrals, Doklady Akademii Nauk SSSR 152, 4 (1963), 808-811.

[18] P. I. Lizorkin, V. B. SHAKHMURov, Embedding theorems for classes of vector-valued functions, Izvestiya Vysshikh Uchebnykh Zavedenii, Mathematika 1 (1989), 70-78, 2 (1989), 47-54.

[19] D. LAMBERTON, Equations d'evalution lineaires associeees a'des semigroupes de contractions dans less espaces $L_{p}$, J. Funct. Anal. 72 (1987), 252-262.

[20] TERry R. MCCONnelL, On Fourier Multiplier Transformations of Banach-Valued Functions, Trans. Amer. Mat. Soc. 285, 2 (1984), 739-757.

[21] G. PISIER, Les inegalites de Khintchine-Kahane d'apres C. Borel, Seminare sur la geometrie des espaces de Banach 7 (1977-78), Ecole Polytechnique, Paris.

[22] M. A. Ragusa, A. TACHIKAVA, Regularity of minimizers of some variational integrals with discontinuity, Zeitschrift fur Analysis und ihre Anwendungen 27 (2008), 469-482.

[23] V. B. Shakhmurov, Embedding and maximal regular differential operators in Sobolev-Lions spaces, Acta Mathematica Sinica 22, 5 (2006), 1493-1508.

[24] V. B. ShaKhmuRov, Coercive boundary value problems for regular degenerate differential-operator equations, J. Math. Anal. Appl. 292, 2 (2004), 605-620.

[25] V. B. Shakhmurov And Rishad Shahmurov, Sectorial operators with convolution term, Mathematical Inequalities and Applications 13, 2 (2010), 387-404.

[26] V. B. SHAKHMURov, Embedding theorems and maximal regular differential operator equations in Banach-valued function spaces, Journal of Inequalities and Applications 2, 4 (2005), 329-345.

[27] C. D. SogGe, Oscillatory integrals, Carleman inequalities and unique continuation for second order elliptic differential equations, J. Amer. Soc. 2 (1989), 491-516.

[28] C. D. SogGe, Fourier integrals in classical analysis, Cambridge press, 1993.

[29] R. S. STRICHARTZ, Restriction of Fourier transforms to quadratic surfaces, Duke. Math. J. 44 (1977), $705-714$.

[30] E.M. STEIn, Singular integrals and differentiability properties of functions, Princeton University Press, Princeton, NJ., 1971.

[31] Z. StRKaLJ, L. Weis, Operator-valued Fourier multiplier theorems, preprint, 2000.

[32] H. TRIEBEL, Interpolation theory. Function spaces. Differential operators, North-Holland, Amsterdam, 1978.

[33] T. WolfF, Unique continuation for $|\triangle u| \leqslant V|\nabla u|$ and related problems, Rev. Mat. Iberoamericana 6, 3-4 (1990), 155-200.

[34] L. WeIS, Operator-valued Fourier multiplier theorems and maximal $L_{p}$ regularity, Math. Ann. 319 (2001), 735-758.

[35] S. YAKUBOV, A nonlocal boundary value problem for elliptic differential-operator equations and applications, Integr. Equ. Oper. Theory 35 (1999), 485-506.

[36] S. YAKubov AND Ya. YAKUbov, Differential-operator equations. Ordinary and Partial Differential equations, Chapmen and Hall CRC, Boca Raton, 2000. 